\title{
Literatura infantil como recurso metodológico para o ensino da matemática inclusiva
}

\author{
Children's literature as a methodological resource \\ for the teaching of inclusive mathematics
}

\section{Flávia Martines de Oliveira ${ }^{1}$ Edvonete Souza de Alencar ${ }^{2}$}

\begin{abstract}
RESUMO: O artigo analisa livros infantis do acervo 1, categoria 3 do Programa Nacional Biblioteca da Escola de 2012 (PNBE) no Brasil, que tratam sobre conteúdos matemáticos e temas relativos à educação inclusiva. Na pesquisa, localizamos vinte e quatro livros infantis do terceiro acervo dos anos iniciais do Ensino Fundamental. Com base na análise de conteúdo, organizamos as categorias dos livros infantis. $\mathrm{O}$ critério para escolha do acervo do PNBE é decorrente do fato deste promover o acesso à cultura e leitura aos professores e estudantes, além de ser de fácil acesso aos livros impressos. O resultado aponta que vinte e quatro livros tratam sobre algum conteúdo matemático e doze obras incentivam a inclusão em suas narrativas. A literatura infantil pode ser um recurso metodológico que encorajam a reflexão sobre a prática docente, bem como o planejamento de estratégias de ensino diversificadas, com finalidade de desenvolver novas situações e propostas didáticas ao ensino da matemática inclusiva nas escolas de educação infantil.
\end{abstract}

Palavras-Chave: Educação Matemática; Literatura Infantil; Ensino Fundamental; Inclusão Escolar.

ABSTRACT: The article analyzes children's books of the collection 1, category 3 of the National Library of the School Program of 2012 (PNBE) in Brazil, which deal with mathematical contents and themes related to inclusive education. In the research, we located twenty-four children's books from the third collection of the initial years of Elementary School. Based on content analysis, we organize the categories of children's books. The criterion for choosing the PNBE collection is due to the fact, that it promotes access to culture and reading to teachers and students, besides being easily accessible to printed books. The result points out that twenty-four books deal with some mathematical content and twelve works encourage inclusion in their narratives. The children's literature can be a methodological resource that encourages reflection on the teaching practice, as well as the planning of diversified teaching strategies, with the purpose of developing new situations and didactic proposals to the teaching of inclusive mathematics in kindergarten.

Keywords: Mathematics Education; Children's Literature; Elementary School; School Inclusion.

\section{INTRODUÇÃO}

Esta pesquisa tem a intenção de investigar quais são os livros infantis do acervo 1 categoria 3 do Programa Nacional Biblioteca da Escola de 2012 (PNBE), que tratam sobre os conteúdos matemáticos, assim como da Educação Inclusiva.

\footnotetext{
${ }^{1}$ Licenciada em Pedagogia pela Universidade de Grande Dourados. E-mail: flaviamartines96@gmail.com

${ }^{2}$ Doutora em Educação Matemática pela Pontifícia Universidade Católica de São Paulo, professora adjunta da Universidade Federal da Grande Dourados, Faculdade de Educação, Curso de Graduação em Pedagogia e professora do quadro permanente do Mestrado Profissional em Educação Científica e Matemática da Universidade Estadual do Mato Grosso. E-mail: edvonete.s.alencar@hotmail.com
} 
De acordo com o Ministério da Educação (MEC), o Programa Nacional Biblioteca da Escola (PNBE) foi criado pelo governo federal, em 1997, com o objetivo de promover o hábito da leitura e ampliar o acesso à cultura e à informação. O programa consiste na distribuição de acervos de obras de literatura, de pesquisa e de referência às escolas públicas do país. Operado pelo Fundo Nacional de Desenvolvimento da Educação (FNDE), autarquia vinculada ao Ministério da Educação, universalizou, em 2005, o atendimento, beneficiando todas as 136.389 escolas públicas brasileiras das séries iniciais - 1 a a $4^{a}$ séries, com ao menos um acervo contendo 20 títulos diferentes. Já, em 2008, de acordo com as diretrizes definidas pelo Plano de Desenvolvimento da Educação (PDE) passou a distribuir também acervos voltados à educação infantil e ao ensino médio.

Como nosso interesse investigativo era buscar os livros no PNBE, realizamos algumas leituras para realização deste trabalho, com foco em: a) o ensino da matemática na educação infantil de Cerquetti-Aberkane (1997); b) a literatura infantil na escola de Smole, Cândido e Stancanelli (1999); c) livros de metodologia científica, como os escritos por Baruffi (2002), Lakatos e Marconi (1992), que compõem o corpo teórico e metodológico da pesquisa.

Assim percebemos que a Matemática é uma ferramenta muito importante para a contribuição da formação do cidadão tanto para o trabalho, relações sociais e para a cultura. E para isso a Matemática veem trabalhando com os conteúdos: contagem, comparação, medidas, cálculos, resolução de problemas, construção de estratégias, comprovação e justificativa dos resultados, conhecimento das formas geométricas, analise e interpretação e conhecimento de diversas formas de abordar problemas.

Podendo ainda estar relacionada com outras áreas de conhecimento como a Ciências por exemplo, quando observamos o desenvolvimento do corpo humano como altura, peso e idade. Vemos assim, a interdisciplinariedade e a importância das relações entre os conhecimentos para a formação do cidadão. Partindo desse principio temos conciência da importância da Literatura Infantil para a realização de um ensino mais inclusivo.

\subsection{LITERATURA INFANTIL PARA O ENSINO DE MATEMÁTICA INCLUSICA}

A Literatura Infantil é destinada especialmente às crianças entre dois a dez anos de idade. $O$ conteúdo de uma obra infantil precisa ser de fácil entendimento pela criança que a lê, seja por si mesma, ou com a ajuda de uma pessoa mais velha. Além disso, precisa ser interessante e, acima de tudo, estimular a criança.

É certo que a linguagem matemática consiste em símbolos bem definidos que representam conceitos fundamentais, mas também é certo que para expressalos oralmente tomamos emprestados termos da língua materna que podem ter diferentes significados dentro e fora da matemática e para construir a compreensão da linguagem unidimensional da matemática faz-se necessário que o aluno tenha noção da diversidade de seu uso (SMOLE, 1999, p.14). 
Smole (1999) sugere a integração do lúdico à curiosidade e à imaginação da criança para que ocorra um ensino significativo, ampliando, desta maneira, as ferramentas para um aprendizado de fácil compreensão sem a rigidez aplicada normalmente. Tal ensino significativo é atribuído à literatura, como papel essencial ao ensino da matemática, por promover o significado das simbologias e do pensamento lógico ao mesmo tempo.

A importância da literatura no âmbito escolar, merece grande atenção. Tendo em vista que a escola possui importante influência no papel social na formação do indivíduo como cidadão, é significativo que a literatura como fonte de conhecimento e de expressividade humana tenha sua ascensão na sala de aula com o intuito de despertar o gosto pela leitura, possibilitando, uma aula produtiva colaborando na formação da identidade literária do aluno. No entanto, há uma grande sistema de numeração decimalde jovens pouco interessados pela literatura. Isto ocorre devido à falta de estímulos e incentivo à leitura, bem como as carências que estão em outras esferas sociais, em especial as condições de ensino e projetos político-pedagógicos que não valorizam a literatura na sala de aula.

Os professores exercem um papel importante como formador da identidade do aluno. Ou seja, o professor é o mediador, para isso é necessário métodos inovadores, aulas mais didáticas e menos mecânicas, que aproximem o aluno da literatura e cative-o a esta vivência da arte, no intuito de valorizar seu desenvolvimento intelectual e sensibilizá-lo diante de obras literárias. É preciso que o professor aproxime a literatura e a matemática à realidade dos alunos.

Ensinar matemática na Educação deve proporcionar aos alunos momentos de exposição de idéias, discussão de resultados e criação, de maneira a quebrar as práticas metódicas, em que a matemática é ensinada apenas por meio de transmissão de conhecimento, defendendo a oportunidade dos alunos realizarem suas descobertas e tornarem se agentes da sua própria aprendizagem. Conforme afirma Cerquetti - Aberkane e Berdonneau (1997):

Lidar com Matemática é antes de tudo, oferecer à criança a oportunidade de agir, e posteriormente levá-la a refletir acerca de suas ações: reviver em pensamento os acontecimentos que acabaram de se desenvolver, antecipar o que poderia vir a acontecer, procurar prever... Desta forma, ela não somente poderá ser confrontada com uma sistema de numeração decimalrazoável de fatos com os quais progressivamente se familiarizará (principalmente através de repetidos contatos), como também, e mais do que isso, irá elaborar imagens mentais relativas a eles, e, ao vinculá-los e dar-Ihes sentido, estruturar pouco a pouco os seus conhecimentos (CERQUETTIABERKANE; BERDONNEAU, 1997, p. 4).

Quanto aos aspectos da Educação Matemática Inclusiva nos referenciamos nos estudos de Vianna (2014), que nos diz:

[...] é fundamental considerar as diferenças e - a partir delas - pensar e pla- 
nejar uma intervenção pedagógica que contemple as funções daquilo que, institucionalmente, é a competência da Escola, enquanto espaço da Educação. Ou seja: não é aceitável o discurso do "Não estamos preparados"! Se isso for verdade, então a questão é: quando estaremos? E o que fazemos enquanto não nos preparamos? O que fazer com a diferença? É preciso pensála sem fazer comparação com "algo". [...] O desafio é pensar a diferença como parte ativa da identidade das pessoas que por ela ou através dela não se tornam nem melhores e nem piores, nem superiores e nem inferiores, elas se tornam "apenas" o que são, e nós convivemos com elas como nós somos e como elas são. [...] Na escola aprendemos, além dos conteúdos, da matemática e da linguagem e de todas as disciplinas, a nos comportar, a nos relacionar com os demais e a ter e valorizar um tipo de saber (VIANNA, 2014, p.8-9)

Assim a inclusão que pretendemos neste trabalho identificar não é somente aos estudantes com necessidades especiais, mas também se refere as diferenças étnicas e as questões sociais e o direito ao conhecimento .

\section{MÉTODO E MATERIAL}

Reiteramos que esta pesquisa tem como objetivo investigar quais são os livros infantis do acervo 1 categoria 3 do Programa Nacional Biblioteca da Escola de 2012 (PN$\mathrm{BE})$, que tratam de assuntos do conteúdo da Matemática, assim como da inclusão.

O presente trabalho caracteriza-se uma pesquisa documental que segundo Marconi e Lakatos (1992), a pesquisa bibliográfica é o levantamento de toda os docuemntso primários já publicados, em forma de livros, revistas, publicações avulsas e imprensa escrita. Os autores ainda orientam os procedimentos para a realização de uma pesquisa documental, no qual indicam a necessidade de leitura do material, escrita de fichamentos e análise por categorias de acordo com o objetivo proposto.

A lista com os livros a serem anaçlisados foi retirada do site do PNBE e os exemplares dos livros para a análise foram conseguidos nas instituições escolares de uma cidade do interior do Mato Grosso do Sul, conforne descritos no Quadro 1:

Quadro 1 - Levantamento de livros selecionados do PNBE:

\begin{tabular}{|l|l|l|}
\hline \multicolumn{1}{|c|}{ LIVRO } & \multicolumn{1}{c|}{ AUTOR } & \multicolumn{1}{c|}{ EDITORA } \\
\hline Contos de fadas & Andersen, Grimm e Perrault & Jorge Zagar \\
\hline Fazedor de tatuagem & Ricardo Azevedo & Uno Educação \\
\hline Exercícios de ser criança & Manoel de Barros & Salamandra \\
\hline Um sujeito sem qualidades & Jean-Claude R. Alphen & Scipione \\
\hline Jardim de Haijin & Alice Ruiz Schneronk - Fê. & Iluminuras \\
\hline A lua dentro do coco & Sergio Capparelli & Projeto \\
\hline Juvenal e o Dragão & Rosinha & Projeto \\
\hline Soprinho - o segredo do bosque encantado; & Fernanda Lopes de Almeida; & Ática \\
\hline $\begin{array}{l}\text { O menino mais feio do mundo: aconteceu no são } \\
\text { João }\end{array}$ & Regina Chamliam & Gráfica e Editora angulo \\
\hline A caminho de casa & Jairo Buitrago & \\
\hline Como um peixe na água & Daniel Nesquens. & UPD \\
\hline
\end{tabular}




\begin{tabular}{|l|l|l|}
\hline Obax & André neves. & Brinque book \\
\hline Joao Esperto leva o presente certo & Candace Fleming & Farol Literário \\
\hline Chapeuzinho vermelho: uma aventura borbulhante & Lynn Roberts & Zastras \\
\hline A procura de Maru & Kumiko Yamamoto & Edições SM \\
\hline De quem tem medo o lobo mau? & Silvana de Menezes & Elementar Publicações e Editora \\
\hline Feminino de menina, masculino de menino & Marcia Leite & Casa da palavra \\
\hline Caraminholas de Barrigapé & Marcos Araújo Bagno & Gráfica e Editora Posigraf \\
\hline Louca por bichos & Miriam Portela & Nova América \\
\hline Superamigos & Noelle Smit & Manati Produções Editoriais \\
\hline O tamanho do meu sonho & Przemyslaw Wechterowicz & Biruta \\
\hline Quando nasce um monstro & Lenice Bueno & Richmond Educação \\
\hline Dez casas E um poste que Pedro fez & Hermes Bernardi Junior & Projeto \\
\hline Arapuca & Daniel Garson Cabral & Positivo \\
\hline Romeu E Julieta & Mariana Massarani & Richmond Educação \\
\hline
\end{tabular}

Realizamos a leitura dos livros infantis e fizemos fichamentos contendo dados básicos da publicação como: nome da obra, ano, editora, autores e ilustradores, resumo da obra e análise de conteúdo matemático e inclusivo. Com análise destes fichamentos realizamos as seguintes categorias: a) livros que tratam de algum conteúdo matemático e b) livros que explanam sobre algum elemento inclusivo.

\section{ANÁLISE DOS LIVROS DE LITERATURA INFANTIL}

Nossas análises foram realizadas em cada livro separadamente observando as duas categorias: se continham indícios em suas histórias ou formato sobre a inclusão ou se possuíam algum conteúdo matemático. Assim apresentamos cada livro, com um breve resumo de sua história e nossas percepções.

Contos de fadas de Perrault et al (2010) é uma obra que contém 26 historias e menciona contos de fadas que quase todos já conhecem, contos compridos com muita escrita e pouca imagem. Observamos que cada uma delas tem uma moral no final. Alguns contos podem ser trabalhados com inclusão e os conteúdos matemáticos encontrados nessa Literatura Infantil alguns conteúdos que podem ser trabalhados em matemática como a noção de tempo, espaço, medidas e grandezas. Percebemos que com este livro é possível introduzir e trabalhar muitas habilidades matemáticas, pois há muitas histórias nele.

Fazedor de tatuagem de Ricardo Azevedo (2010) é uma história de um menino que sonha em ser tatuador, mas mal sequer sabe desenhar, então passa por longos caminhos e seu destino é seguir pensando na vida, vendo tudo em sua volta e principalmente desenhando muito para conseguir realizar seu sonho. Depois de muitos esforços o garoto consegue seu trabalho de ser tatuador. Os conteúdos matemáticos encontrados nessa Literatura Infantil foram: noção de tempo, sistema de numeração decimal, medidas e grandezas e não encontramos inclusão nesta história.

O livro Exercícios de ser criança de Barros (2009) contém duas histórias: O menino que carregava água na peneira e A menina avoada. O menino que carregava água na peneira: é uma história em forma de poesia conta sobre um menino que carregava água na 
peneira e que sua mãe mostra o que significa em outros ditos populares. O menino com o tempo se torna diferente dos outros, gosta de coisas que outro menino talvez não iria gostar, então o menino começou a escrever e que escrevendo poderia ser o que quisesse ou fazer coisas que na vida real não poderia e por fim a sua mãe descobre que seu filho vai ser poeta e que sempre carregará água na peneira. Nessa primeira história contem conteúdos matemáticos de: medidas como cheio e vazio, noção de tempo. E identificamos que a história trabalha sobre as diferenças de gostos, brincadeiras e hábitos pessoais.

A segunda história é $A$ menina avoada. A menina conta a história dela e do irmão de quando eram mais novos que na fazenda estavam brincando, seu irmão pegou um caixote e imagina que estava em um carro de boi e que era puxado por dois bois, então eles imaginavam que estavam indo para a cidade e seu irmão tinha que ir ver sua a namorada imaginaria e no caminho acontecia várias coisas até que chegavam no fim do quintal e a brincadeira deles acabava.Neste segundo texto o conteúdo matemático é: noção de tempo, sistema de numeração decimal, noção de posição e grandeza e medidas. Não encontramos inclusão nessa história.

A história um sujeito sem qualidades de Alphen (2010) nos diz sobre Arnaldo e como ele vive sozinho, morava em uma montanha em uma casa de madeira, perto do rio. A casa dele ficava a oito mil e oitocentos metros acima do nível do mar e todos tinham medo dele. E se achava tão bom no que fazia podia se dizer que era formado e pós-graduado. Durante o dia distribui seus afazeres, de manhã gosta de levantar bem cedo ver o nascer do sol e tomar seu banho com água gelada e com seu grunhido assustava os vizinhos. A tarde sentava em uma rede e olhava as plantas crescerem que para ele era uma especialidade de muita paciência, ao quase anoitecer toma seu lanche, meia dúzia de trutas ao molho de pinhão com manteiga de garrafa.

E por fim do seu dia, colocava sua cadeira no deque de madeira e sentava para ver o maior espetáculo da terra o pôr do sol e depois ia dormir.Mas Arnaldo descobriu que estava faltando algo, até que descobriu que faltava alguém para compartilhar suas emoções. Então foi a procura, ele tinha três espécies de aves que eram seus vizinhos: os sanhaços, as gralhas e pardais.Então ele foi até os sanhaços, lindos pássaros e cantos maravilhosos, mas para o Arnaldo era só barulho mesmo.

Mas mesmo assim tentou fazer amizade com as aves e então resolver descrever para elas, mas sua fome falou mais alto e sem pensar quis comer seu prato preferido e as aves tiraram sarro do monstro e fugiram. Decidiu ir até as gralhas, conversam muito e falam de todos. Mesmo assim Arnaldo foi tentar contar uma história para elas, mas o sono fez ele abrir seu bocão e a gralhas riram dele. Mas, ele queria muito novas amizades e foi tentar com os pardais, foi falar do rio, mas acabou dormindo. Arnaldo viu que não iria dar certo e ficou se achando um artista incompreendido e voltou para sua casa e continuar a ser ele mesmo um sujeito muito sensível. Neste texto encontramos indícios dos conteúdos matemáticos de: sistema de numeração decimalnoções de tempo, noções de grandezas, dúzia e meia dúzia e números. Não encontramos inclusão nesta his- 
tória.

O Jardim de Jaijin de Ruiz (2010) trata-se de um livro com versos poético mostra o mundo diferente, temos que se esforçar para o próximo para depois olhar para nós mesmos. Faz um trabalho inclusivo mostrando as diferenças e que somos diferentes.Encontramos índicos dos conteúdos matemáticos ao se trabalhar rima nos versos poéticos, permitindo trabalho com a igualdade, que promove desenvolver o pensamento algebrico Ferreira, Ribeiro e Ribeiro (2016).

A lua dentro do coco de Capparelli (2010) conta a história em formas de rimas de um macaquinho que achou um coco e tinha um pouquinho de água dentro. Então sua sede morreu, ele viu o sol se pôr e a lua nascer e lembra da morte da sua mãe, mas logo volta a brincadeira, mas o bugio chama todos para dormir.E surge discussões sobre a lua, do que é feita a lua como ela é e de quem é. Até que o macaquinho pega seu coco e vê a lua refletida na água que está dentro do coco. Eles brigam por causa da lua e então o coco cai e eles ficam sem a lua, até que o bugio vê a lua lá em cima e mostra a todos.Nesta história podemos trabalhar com conteúdo matemático: sistema de numeração decimal, noções de grandezas, noções de posições, noções de direção e sentido, geometria e noções de capacidade, desenvolvimento do pensamento algébrico: igualdade.

Juvenal e o Dragão é uma história contada em cordel. Em um reino todos os anos o dragão ataca e o rei envia uma moça linda para ser sacrificada, então neste ano a princesa será levada. No caminho aparece o Juvenal que luta com o dragão e ganha a luta, depois se despede da princesa e segue seu caminho. No caminho o cocheiro ameaça a princesa a dizer que foi ele que matou o dragão, e o rei ordena a princesa a se casar com o cocheiro e ela reza para Juvenal voltar e a salvar. O Juvenal sente que está acontecendo algo e vai ao reino e sabe do que está acontecendo e luta com os soldados. O rei vê as lutas e a princesa contam a verdade e o cocheiro vai preso e condenado a morte e o Juvenal se casou com a princesa. Os conteúdos matemáticos identificados são: sistema de numeração decimal, noção de tempo, noções de posição, desenvolvimento do pensamento algébrico: igualdade. Não encontramos inclusão nesta história.

Soprinho - o segredo do bosque encantado de Fernanda Lopes de Almeida (2008) é uma história que conta de um menino que tem o poder de fazer ver o mundo diferente, basta receber o sopro e descobrir um mundo de magia e desvenda um enigma. Descobre quem é mau e quem é ruim para a natureza e ainda faz pensar o que será bom e o que será ruim para nossa vida. É uma história de criança tentando mudar a natureza. Esta história proporciona o trabalho com figuras, sistema de numeração decimal, tempo, espaço, medidas e grandezas. Não encontramos inclusão nesta história.

O menino mais feio do mundo: aconteceu no São João de Regina Chamliam (2011) é uma história sobre um menino chamado Bertoldinho, considerado feio e que morava com a mãe consertadora de bonecos. O menino também aprendeu a consertar. Bertoldinho cresceu e se tornou gentil e mais feio, um dia perto das festas juninas chegou um grupo para arrumar os preparativos para uma grande atração. Muita gente foi e todos queriam aproveitar a festa e o Bertoldinho se arrumou e deixou uma carta para sua mãe. 
E então aproveitou tudo o que tinha na festa como a peça de teatro que assistiu.

Depois algumas pessoas chamaram ele para ver o menino mais feio do mundo, quando chegou na festa e olhou para o espelho viu seu próprio reflexo e todos começaram a rir do menino e a menina que ele mais gostava o chamou de o menino mais feio do mundo. Então ele corre e entra em uma tenda cheia de espelhos e logo sai. Depois entra em outra sala, um lugar lindo e surge uma mulher que pergunta o que ele quer e então ele pede para ficar bonito e quer pagar, mas a mulher diz que não pois boniteza cada tem a sua e vai construindo durante a vida. Mas mesmo assim o menino insistiu e a mulher concordou mas disse que não era uma boa ideia. O menino teria que encontrar com o capeta e fazer um pacto.

Quando o menino achou o capeta conversou com ele e disse que queria ser bonito, mas o capeta disse a ele que o mesmo seria bonito e ruim. Assim o menino concordou e o capeta então pegou sua sombra e guardou. Ao retornar à festa dançou com Solange e a lua surgiu e somente a sombra de Bertoldinho que não apareceu e apenas a Selene que viu. Muitas coisas de ruim o menino fez, com a Selene ele teve a ajuda para ir ao inferno busca de sua sombra, até que conseguiu com muita dificuldade. Quando de repente vê no medalhão da mulher que havia mostrado no começo da história. Então ele vê o que iria acontecer com ele se ele fizesse o pedido de ficar bonito. Ele sai da barraca e dança apaixonadamente com Selene.

Este livro tem como conteúdo matemático: noção de tempo, sistema de numeração decimal, noções de grandezas e inclusão.

A caminho de casa de Jairo Buitrago (2010) é uma história de uma menina que pede a um leão para acompanhar ela até a casa, para que ele converse, pois, o caminho e longo na grande cidade, para que possa andar bem rápido, fazer compras, comer e esperar a mãe da volta do trabalho. A menina quer o leão para proteger ela e substituir a falta do pai.Essa história contém conteúdos matemáticos: noção de tempo, conceitos de rápido e devagar. Não encontramos inclusão.

Como um peixe na água de Daniel Nesquens (2012) é uma história sobre um menino cadeirante chamado Sebastiao que sabe nadar muito bem, ele adora tudo que se refere a água. De manhã primeira coisa que faz é olhar como está o céu, se está limpo ele fica triste mas se esta nublado fica feliz e se está chovendo ele fica muito feliz. Ele quer ser chamado de oceano. Ele quer ser um bom nadador e participar das olimpíadas de 2020 e bater os recordes de natação. Quando está em dias quentes perde a vida e logo vai nascer escamas e barbatanas nele. Os conteúdos matemáticos encontrados nessa Literatura Infantil foram: Noção de tempo, noções de posições, sistema de numeração decimal , noções de grandezas e inclusão.

Obax de André Neves (2010) trata de uma menina que adora se aventurar onde morava, e vivia na África. Era muito sozinha sem amigos, ninguém se importava com ela. Depois que contou uma história e ninguém acreditou nela decidiu nunca mais contar suas histórias e fugiu em busca de uma prova que sua história era verdade, com um elefante a menina deu a volta ao mundo e não conseguiu sua prova. Mas passou por tudo 
no caminho, e até que chegaram na savana novamente.

Ela contou suas histórias e ninguém acreditou. Então ela buscou o elefante para provar e quando viram era uma pequena pedra em forma de elefante, então ela decide enterrar a pedra. No dia seguinte no local onde estava a pedra havia nascido um pé de baobá muito florido e todos passaram a acreditar na menina. Essa história possui muitas imagens e escritas, figuras que podem trabalhar as formas geométricas, tempo, espaço, sistema de numeração decimal. Observamos também o trabalho com a inclusão pois a menina é negra e excluída e tenta se socializar e fazer amizades.

João Esperto: leva o presente certo de Candace Fleming (2010) é uma história de um menino chamado Joao que foi convidado para o aniversário da princesa, mas ele e nem sua mãe tem condições de comprar presente. Então ele decide fazer um bolo e busca o que precisa. O bolo fica lindo com duas camadas, dez velinhas azuis e com as nozes escrito "feliz aniversário" e morango. Quando ia levar o presente da princesa, no caminho encontrou corvos que voaram em cima do bolo e quando João disse que era para princesa os pássaros foram embora. Então seguiu com o bolo faltando as nozes.

Quando chegou na ponte o ogro queria que o menino pagasse o pedágio então João deu uma camada do bolo em pagamento para poder seguir para a festa com apenas uma camada, as velas e o morango. Quando chegou na floresta e com medo acendeu uma vela, mas rapidamente a vela acabou e então João acendeu outra e até que acendeu a última e achou a estrada. Seguiu com o bolo com uma camada e o morango apenas.

No caminho para o castelo encontrou uma cigana com um urso e quando ele foi dançar com seus novos amigos o urso comeu o bolo e o morango ficou. E então olhou para o presente e viu que ainda tinha restado apenas o morango.Quando chegou no castelo, entrou onde estava ocorrendo a festa e quando foi entregar o presente da princesa o guarda disse que a princesa tinha alergia a morango e comeu, quando chegou a vez do João entregar o presente contou sua história triste sobre o bolo que lhe ia dar e então a princesa adorou a história e achou que foi o melhor presente.

Os conteúdos matemáticos encontrados nessa Literatura Infantil foram: noção de tempo, sistema de numeração decimal, noções de massa, noções de direção e sentido, noções de capacidades, adição e subtração. E não encontramos inclusão na história.

Chapeuzinho vermelho: uma aventura borbulhante de Lynn Roberts (2009) é uma história que conta de um menino chamado Tomás, que usava um casaco vermelho e todos chamavam ele de chapeuzinho vermelho. Ele e seus pais era donos de uma pensão e tinham refrigerantes borbulhantes. Sempre gostava de ir visitar sua avó e levava uma cesta de coisas gostosas e um garrafão de refrigerante. Neste dia foi visitar a avó e no caminho encontrou macas e quis pegar uma para sua avó e o lobo estava observando o menino escondido.

O menino deixou seu casaco em uma pedra e então o lobo pegou e foi para a casa da vovó e chegou lá comeu a vovó e vestiu a roupa da vovó para quando o chapeuzinho vermelho chegasse pudesse engana-la. Então quando o menino entrou na casa o lobo já 
estava esperando. Quando o lobo ia comer o menino, Tomás teve a ideia de oferecer só refrigerante e o lobo tomou e deu aquele arroto que vovó saiu voando da barriga do lobo. E com o garrafão o menino fez o lobo desmaiar. E o lobo prometeu que não ia comer mais ninguém em troca do refrigerante toda semana, pois ele gostou muito do refrigerante borbulhante.

Os conteúdos matemáticos encontrados nessa Literatura Infantil foram: noção de tempo, sistema de numeração decimal, noções de capacidade, de grandezas, de posições. Não encontramos inclusão na história.

A procura de Maru de kumiko Yamamoto (2009) é uma história de uma família japonesa. Takeru tem um cachorro chamado Maru. Maru destrói uma flor que Takeru plantou e então ele briga com o cão, Maru desaparece e o menino procura seu cachorro e não o acha. Então decide sair para procurar e estava chovendo. O personagem passa por vários desafios e lugares perigosos e volta para casa sem achar seu cachorro, quando ele chega em casa o cachorro Maru estava esperando por Takeru em sua casa. Os conteúdos matemáticos encontrados nessa Literatura Infantil foram: noção de tempo, noções de capacidade, de posições, formas geométricas. Não encontramos inclusão.

De quem tem medo o lobo mau? de Silvana de Menezes (2009) é uma história de um velho lobo, que vivia sozinho e até que um dia encontrou um caçador, mas seus extintos já não eram mais os mesmos e quando o homem perguntava de suas orelhas, oIhos, boca, focinho ao invés de responder que eram para melhor ele respondia para pior, pois já não era mais jovem.

Encontramos inclusão e os conteúdos matemáticos encontrados nessa Literatura Infantil foram: noção de tempo, medidas e grandezas.

Feminino de menina, masculino de menino de Marcia Leite (2011) é uma história que aponta as diferenças entre meninos e meninas, coloca seus defeitos e qualidades de cada um. Também fala o que cada um pode fazer e que cada um pode fazer o que o outro faz, sem diferenças entre meninas e meninos. Os conteúdos matemáticos encontrados nessa Literatura Infantil foram: medidas e grandezas, sistema de numeração decimal, noções de tempo e encontramos a inclusão nesta história.

Caraminholas de Barrigapé de Marcos Bagno (2011) é uma história de um caramujo chamado Barrigapé. Esse caramujo é pequeno e vive em um grupo de caramujos que não pensam igual a ele. Ele tem um sonho de voar e os outros sabem que é impossível, e esses outros caramujos não se importam com ninguém já o Barrigapé pensa nas dificuldades dos outros. Até que começou a ventar muito no brejo e o caramujo teve uma ideia de subir em uma folha seca que era grande e suportaria seu peso e então o vento soprou e o caramujo voou e seus amigos até pensaram que ele era um bruxo.

Ele viu que podia fazer outros tipos de aventuras como nadar, viajar, entrar numa casa ver os humanos. Então falou com um menino e então os outros caramujos tornaram o Barrigapé num grande herói dos caramujos, mas o Barrigapé não quis o título de heróis e entrou na sua casa e não quis mais sair e decidiu escrever uma carta sobre sua história e entregou para o menino chamado Amadeus. 
Essa obra da literatura infantil possui uma grande quantidade de ilustrações e escritas que permitem melhor entendimento da história. E é um livro que da para trabaIhar matemática com conteúdo como sistema de numeração decimal, tempo, espaço, medidas e grandezas e formas geométricas e não encontramos inclusão nessa história.

Loucas por bichos de Miriam Portela (2009) essa história conta da Miriam, que desde cedo começou a falar a língua dos animais. Aprendeu com o galo Bebeto, com o coeIho Estevão, e até com uma vaca malhada chamada Brigitte. E assim foi com cada bichinho que passou por sua vida ao longo dos anos. Ela já falou "cachorrês", "maritaquês" e "gatês" que agora ela inventou um novo companheiro de jornada um gato preto chamado Hermes. Os conteúdos matemáticos encontrados nessa Literatura Infantil foram: medidas de tempo, sistema de numeração decimal, medidas de grandeza e inclusão.

Superamigos de Fiona Rempt (2010) é uma história sobre o dia do aniversário de caramujo e a festa é na floresta. Todos os seus amigos foram comemorar com ele e este por ser lento não acompanhavam os outros animais. Na hora do bolo ele assoprou as velas e fez um pedido, depois foi a vez de desembrulhar os presentes e então cada animal trouxe um presente que por acaso era de suas funções para sobreviver na floresta. Quando acabou de abrir todos os presentes veio a melhor parte seus amigos pegaram todos os presentes e montou um único carro para ele ser veloz e seu pedido secreto foi realizado.

Essa história tem como princípio trabalhar com a quantidade de amigos e de presente e depois que fizeram o carro quantos presente ficaram, também trabalha as noções de tempo, pois foi o aniversário do caramujo e grandezas que foram os tamanhos dos presentes e tamanho dos animais que tinham de vários tamanhos. Além do trabalho com as questões de velocidade. E não encontramos inclusão nessa história.

O tamanho do meu sonho de Przemyslaw Wechterowicz (2010) é uma história em formas de rimas. E todos da história tem um sonho de ser, fazer, de ter algo. A cegonha quer ir para uma ilha e ter uma filha, as enguias sonhas em escalar a montanha, o fogo quer ser bombeiro, a aleluia em ser alegre, os cavalos marinhos ter uma banda de rock, o tapete em voar e ir para marte, o poço em mergulhar no oceano, o rio sonha em ser rápido e dar uma volta na formula 1, a coruja em ser mãe, a lombriga por ser parasita e não poder sonhar, queria sonhar, o arranha céu tem vergonha em dizer seu sonho, o sol em ter um óculos escuro, o vento quer ser um leque e abanar uma pessoa só, o espantaIho quer um amigo de verdade que não se assuste com ele, o colibri sonha em ter um par de assas extras e carregar na mochila, a chaminé em tirar uma soneca, o forno em ser uma nuvem, o tubarão ter cabelo comprido, os sapatos vermelhos quer ir a um concerto. Todos temos e podemos ter um sonho.

Os conteúdos matemáticos encontrados nessa literatura infantil foram: sistema de numeração decimal, medidas e grandezas, grande e pequeno no caso e encontramos inclusão nesta história.

Quando nasce um mostro de Lenice Bueno (2009) é uma história de um monstro que quando nasce tem que se encaixar em algum lugar e se algo não der certo para ele 
tem duas possibilidades como: ou ele é um monstro da floresta distante ou um monstro que fica debaixo da cama. E dependendo do caminho ele terá as suas duas possibilidades e assim vai seguindo o caminho diferente se algo der errado. Nessa história encontramos inclusão, pois o monstro tenta se enturmar e os conteúdos matemáticos encontrados nessa Literatura Infantil foram: sistema de numeração decimal, medidas e grandezas.

Dez casas e um poste que Pedro fez de Hermes Bernardi Jr. (2010) é uma história em forma de poema e conta de uma rua que tem dez casas e cada casa vive uma pessoa diferente e cores diferentes e um poste que ilumina a rua inteira e um endereço que se chama avenida das cores, por todo lugar.Nessa história encontramos inclusão, pois pode morar qualquer um na avenida e todos diferentes. Os conteúdos matemáticos encontrados nessa Literatura Infantil foram: sistema de numeração decimal, formas geométricas, e medidas dos seres que moravam nas casas.

Romeu e Julieta de Ruth Rocha (2011) é uma história de um reino que há muito tempo que tudo era separado por cores. O que era branco tinha que ficar andando com o que era branco. No canteiro amarelo morava uma borboleta amarela chamada Julieta e não podia voar para outro canteiro de outra cor. No canteiro azul morava borbotas azuis e tinha uma borboleta chamada de Romeu e seu amigo Ventinho chamou Romeu para passear em outro canteiro e disse que tinha uma amiga chamada Julieta e que era amarela.

Depois que foram apresentados um ao outro viraram amigos e fizeram muitas coisas juntos. Até que entraram em perigo, um humano queria eles para sua coleção, então o ventinho assoprou poeira nos olhos do garoto e pediu que Romeu e Julieta fugissem. E perdidos na floresta passaram a noite e quanto na casa de um deles os pais ficaram preocupados e foram de canteiro em canteiro procurar seus filhos até encontrarem as duas borboletas e fizeram uma grande comemoração com todas as borboletas de todos os canteiros, todas as cores juntas.

Os conteúdos matemáticos encontrados nessa Literatura Infantil foram: sistema de numeração decimal, noção de tempo e espaço. E não encontramos inclusão nessa história.

Assim para termos uma melhor visualização de nossas análises fizemos um quadro síntese com a indicação de quais categorias as obras apresentam:

Quadro 2 - Quadro síntese da análise de conteúdo dos livros infantis:

\begin{tabular}{|l|c|c|}
\hline \multirow{2}{*}{ OBRAS LITERÁRIAS } & \multicolumn{2}{c|}{ CATEGORIAS } \\
\cline { 2 - 3 } & ABORDA CONTEÚDOS MATEMÁTICOS & ABORDA ASPECTOS INCLUSIVOS \\
\hline Contos de fadas & $\mathrm{X}$ & $\mathrm{X}$ \\
\hline Fazedor de tatuagem & $\mathrm{X}$ & \\
\hline Exercícios de ser criança & $\mathrm{X}$ & $\mathrm{X}$ \\
\hline Um sujeito sem qualidades & $\mathrm{X}$ & $\mathrm{X}$ \\
\hline Jardim de Haijin & $\mathrm{X}$ & \\
\hline A lua dentro do coco & $\mathrm{X}$ & $\mathrm{X}$ \\
\hline Juvenal e o dragão & $\mathrm{X}$ & \\
\hline Soprinho - O segredo encantado & $\mathrm{X}$ & \\
\hline $\begin{array}{l}\text { O menino mais feio do mundo: aconte- } \\
\text { ceu no São Joao }\end{array}$ & & \\
\hline
\end{tabular}




\begin{tabular}{|l|l|l|}
\hline A caminho de casa & $\mathrm{X}$ & $\mathrm{X}$ \\
\hline Como um peixe na água & $\mathrm{X}$ & $\mathrm{X}$ \\
\hline OBAX & $\mathrm{X}$ & \\
\hline Joao esperto leva o presente certo & $\mathrm{X}$ & \\
\hline $\begin{array}{l}\text { Chapeuzinho vermelho: uma aventura } \\
\text { borbulhante }\end{array}$ & $\mathrm{X}$ & $\mathrm{X}$ \\
\hline A procura de Maru & $\mathrm{X}$ & $\mathrm{X}$ \\
\hline De quem tem medo o Lobo mal? & $\mathrm{X}$ & \\
\hline $\begin{array}{l}\text { Feminino de menina, masculino de } \\
\text { menino }\end{array}$ & $\mathrm{X}$ & $\mathrm{X}$ \\
\hline Caraminholas de Barrigapé & $\mathrm{X}$ & \\
\hline Louca por bichos & $\mathrm{X}$ & $\mathrm{X}$ \\
\hline Superamigos & $\mathrm{X}$ & $\mathrm{X}$ \\
\hline O tamanho do meu sonho & $\mathrm{X}$ & $\mathrm{X}$ \\
\hline Quando nasce um monstro & $\mathrm{X}$ & \\
\hline Dez casas e um poste que Pedro fez & $\mathrm{X}$ & \\
\hline Romeu e Julieta & $\mathrm{X}$ & \\
\hline
\end{tabular}

\section{CONSIDERAÇÕES FINAIS}

Neste trabalho, analisamos os livros infantis do acervo 1, categoria 3 do Programa Nacional Biblioteca da Escola (PNBE), tendo como foco identificar os conteúdos matemáticos abordados e temas relacionados a inclusão escolar. Do material analisado, vinte quatro livros tratam de conteúdos matemáticos e doze abordam aspectos inclusivos em suas narrativas.

A literatura infantil pode ser um recurso metodológico que incentiva a reflexão sobre a prática docente, bem como o planejamento de estratégias de ensino diversificadas, com finalidade de desenvolver novas situações e propostas didáticas ao ensino da matemática inclusiva.

O estudo tem suas limitações, mas seu resultado é significativo por direcionar a pensar sobre o uso da Literatura Infantil no ensino de matemática, numa perspectiva inclusiva às turmas de educação infantil, visando fomentar a elaboração de atividades didáticas e abordagem de ensino da matemática inclusiva no sistema escolar.

Assim, com a produção deste artigo, almejamos contribuir com as pesquisas em educação matemática, com ênfase nas discussões sobre inclusão escolar na educação infantil no Brasil.

\section{REFERÊNCIA}

ALMEIDA, F. L. Soprinho: o segredo do bosque encantado. Ilustrações de Odilon Moraes. São Paulo: Ática, 2008.

ALPHEN, J-C. R. Um sujeito sem qualidades. Ilustrações do autor. São Paulo: Scipione, 2010.

AZEVEDO, R. Fazedor de tatuagem. Ilustração de do autor. São Paulo: Uno Educação, 2011.

BAGNO, M. Caraminholas de Barrigapé. Ilustrações de Cris Eich, Curitiba: Posigraf, 
2011.

BARROS, M. Exercícios de ser criança. llustrações e bordados do grupo Matizes Dumont, coordenado por Martha Dumont. Rio de Janeiro: Salamandra, 2009.

BERNANDI JR, H. Dez casas e um poste que Pedro fez. Ilustrações do autor. Porto Alegre: Ed. Projeto, 2010.

BRASIL. Ministério da Educação. Disponível em: http://portal.mec.gov.br/programanacional-biblioteca-da-escola/acervos, Acesso: 29 de novembro de 2017.

BUITRAGO, J. A caminho de casa. Ilustrações Rafael Yockteng. São Paulo: Ed. UDP, 2010.

BARUFFI, H. Metodologia científica: Manual para elaboração de monografias, dissertações, projetos e relatórios de pesquisas. 3. ed. rev. e atual. Dourados: Hbedit, 2002.

CAPPARELLI, S. A lua dentro do coco. Ilustrações de Eloar Guazzelli Filho. Porto Alegre: Ed. Projeto, 2010.

CERQUETTI-ABERKANE, F. O ensino da matemática na educação infantil. Porto Alegre. Artes Médicas, 1997.

CHAMLIAN, R. O menino mais feio do mundo: aconteceu no São João. llustrações de Helena Alexandrino. São Paulo: Ângulo, 2011.

FERREIRA, M; RIBEIRO A.; RIBEIRO, M. Álgebra nos anos iniciais do ensino fundamental: primeiras reflexões à luz de uma revisão de literatura. Educação e Fronteiras On-Line, Dourados, v. 6, n.17, p. 34-47, Maio./Ago. 2016.

FLEMING, C. João esperto leva o presente certo, ilustrações de G. Brian Karas. São Paulo: Farol Literário, 2010.

LAKATOS, M. E; MARCONI, M. A. Fundamentos de metodologia científica. 4.ed. São Paulo: Atlas, 1992.

LEITE, M. Feminino de menina, masculino de menino, ilustrações de Sônia Magalhães. Rio de Janeiro: Casa da Palavra, 2011.

MENEZES, S. De quem tem medo o lobo mau? São Paulo: Elementar, 2009.

NESQUENS, D. Como um peixe na água. Ilustração de Rick Blanco. São Paulo: Cosac Naify, 2012.

NEVES, A. Obax. llustração do autor. São Paulo: Brinque-Book, 2010.

PERAULT, G. A. et. al. Contos de fadas. Tradução Maria Luiza. Rio de Janeiro: Ed. Zahar, 2010.

PNBE. Programa Nacional da biblioteca na Escola. Disponível em: http://portal.mec.gov. br/observatorio-da-educacao/195-secretarias-112877938/seb-educacao-basica-20070 48997/12516-pnbe. Acesso: 21 de fev. de 2018. 
PORTELA, M. Louca por bichos, obras de Gustavo Rosa. São Paulo: Noovha America, 2009.

REMPT, Fiona. Superamigos. Ilustrações de Noelle Smit. Rio de Janeiro: Manati, 2010.

ROBERTS, L. Chapeuzinho vermelho: uma aventura borbulhante. Ilustrações de David Roberts. São Paulo: Zastras, 2009.

ROCHA, R. Romeu e Julieta. Ilustrações de Mariana Massarani. São Paulo: Richmond Educação, 2011.

ROSINHA. Juvenal e o Dragão. Ilustrações da autora. Porto Alegre: Ed. Projeto, 2011.

RUIZ, A. Jardim de Haijin. São Paulo: lluminuras, 2010.

SMOLE, K. C. S.; CÂNDIDO, P. T.; STANCANELLI, R. Matemática e Literatura Infantil. 4.ed. Belo Horizonte: Ed. Lê, 1999.

TAYLOR, S. Quando nasce um monstro. Ilustrações de Nick Sharratt. São Paulo: Richmond Educação, 2009.

VIANNA, C. R. Uma ilha de inclusão no mar de exclusão? Pacto Nacional pela Alfabetização na Idade Certa: Educação Inclusiva. Brasília: MEC; SEB, 2014.

WECHTEROWICZ, P. O tamanho do meu sonho. Ilustrações de Marta Ignerska. São Paulo: Biruta, 2010.

YAMAMOTO, K. A procura de Maru. Tradução de Rodrigo Villela. São Paulo: Edições SM, 2009.

(c) (†)

License information: This is an open-access article distributed under the terms of the Creative Commons Attribution License, which permits unrestricted use, distribution, and reproduction in any medium, provided the original work is properly cited.

Article received on April 26, 2018.

Accepted on October 30, 2018. 